$\cos 8-9411137-1$

\title{
Adventures in Supercomputing, a K-12 Program in Computational Science: \\ An Assessment
}

\author{
C. Edward Oliver \\ H. Richard Hicks \\ Computing, Networking, Informatics and Education \\ Oak Ridge National Laboratory* \\ P. O. Box 2008 \\ Oak Ridge, TN 37831-6486 \\ Kimberly D. Iles-Brechak \\ Vanderbilt University \\ P. O. Box 2008 \\ Oak Ridge, TN 37831-6259 \\ Margaret Honey \\ Katherine McMillan \\ Education Development Center \\ 96 Morton St. \\ New York, NY 10014
}

RECEIVED

SEP $2319: 44$

OSTI

To be presented at the Frontiers in Education Conference, San Jose, CA, November 3 -6, 1994; to be published in the Proceedings.

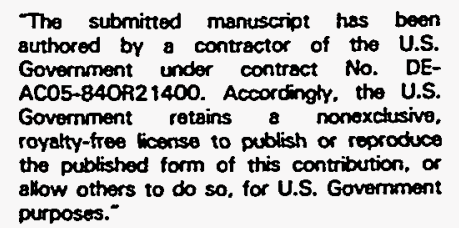

*Managed by Martin Marietta Energy Systems, Inc. under contract DE-AC05-84OR21400 with the U.S. Department of Energy

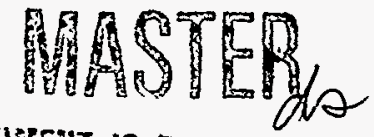




\section{DISCLAIMER}

Portions of this document may be illegible in electronic image products. Images are produced from the best available original document. 


\section{Adventures in Supercomputing, a K-12 Program in Computational Science: An Assessment}

\section{Edward Oliver \\ H. Richard Hicks Oak Ridge Natlonal Laboratory *}

\author{
Kimberly D. lles-Brechak \\ Vanderbllt University
}

\author{
Margaret Honey \\ Katherine McMillan \\ Education Development Center
}

\section{INTRODUCTION}

The Department of Energy Adventures in Supercomputing (AiS) program for high school teachers is described in detail in Session 3D4. In this paper, we will describe only those elements of the program, such as school selection, which have a direct bearing on assessment.

Schools submit an application to participate in the AiS program. They propose a team of at least two teachers to implement the AiS curriculum. The applications are evaluated by selection committees in each of the five participating states to determine which schools are the most qualified to carry out the program and reach a significant number of women, minorities, and economically disadvantaged students, all of whom have historically been underrepresented in the sciences.

Typically, selected schools either have a large disadvantaged student population, or the applying teachers propose specific means to attract these segments of their student body into AiS classes. Some areas with AiS schools have significant numbers of minority students, some have economically disadvantaged, usually rural, students, and all areas have the potential to reach a higher proportion of women than technical classes usually attract.

This report presents preliminary findings based on three types of data: demographic, student journals, and contextual. Demographic information is obtained for both students and teachers. Students have been asked to maintain journals which include replies to specific questions that are posed each month. An analysis of the answers to these questions helps to form a picture of how students progress through the course of the school year. Onsite visits by assessment professionals conducting student and teacher interviews, provide a more in depth, qualitative basis for understanding student motivations.

The final assessment element is the analysis of videotapes (Roschelle, J., \& Fredriksen, J., 1992) of participating students describing their AiS projects, and answering some carefully posed questions. These tapes are then analyzed by trained personnel to extract key information. The results of this element are not complete, and thus are not reported on here.
Other possible measures of program success are not analyzed here, such as the number of student mentors and the amount of financial support from the community (in kind, equipment, and grants). This local support is known to be approximately as large as the yearly Department of Energy investment.

\section{DEMOGRAPHIC DATA}

\section{Student demographics}

In spite of the tendency of female high school students to self-select out of elective technical courses, female participation has increased to $46 \%$ of AiS students, from $39 \%$ in the preceding year. Minority participation has, likewise, increased to $38 \%$ from $29 \%$. This compares to only $25 \%$ minority participation in science and mathematics classes in general (NCES, 1993).

\section{Teacher demographics}

A questionnaire distributed to teachers at the fall teacher workshops in each state was designed to collect information on teaching experience, general teacher demographics, subject area specialty, grade levels taught, and experience with educational technology.

Teacher sex and ethnicity. The distribution of male and female AiS teachers is almost identical to the national distribution. The AiS group is $66 \%$ female $33 \%$ male, compared to $71 \%$ female $29 \%$ male nationally.

The ethnic distribution of teachers is also similar to the national distribution: Caucasian teachers make up $86.2 \%$ of the AiS group, $10.3 \%$ are African-American, and 3.4\% are Hispanic, while the national profile is $88.1 \%$ Caucasian, 7.3\% African-American, and 2.6\% Hispanic.

Years teaching. The teachers involved in the AiS program are highly experienced educators. Almost half $(47 \%)$ have taught for more than twenty years, while only $23 \%$ of teachers nationwide have taught this long (NCES, 1992).

Primary teaching assignment and grade levels. Almost half (47\%) of these teachers describe their primary teaching assignment as some form of mathematics. A third (33\%) of them are science teachers, and $20 \%$ teach computer science 
or programming courses. All the AiS teachers teach tenth, eleventh, and twelfth graders; most (73.3\%) teach ninth grade as well, and $13 \%$ also teach eighth grade classes.

Experience with and access to technology. The AiS teachers report an average of six years experience with educational technology. However, this average represents a group that is almost evenly divided between highly experienced and novice users of educational technology. A survey of teachers recommended as accomplished users of educational technology, carried out by the Center for Technology in Education, suggested that approximately five to seven years of experience using educational technologies in the classroom was necessary in order for a teacher to consider her or himself an accomplished and comfortable user of technology (Sheingold \& Hadley, 1988). Among the AiS teachers surveyed, 15 of 30 have used technology for educational purposes for only one or two years. Only one teacher falls into a mid-range of three to four years of use. The remaining fourteen teachers have all used educational technology for more than five years, suggesting that they are highly experienced and knowledgeable users.

Home technology access. $60 \%$ of AiS teachers report that they have a computer at home. Only $33 \%$ have a modem at home.

Teaching AiS alone or with a colleague. Half of the AiS teachers report that they teach AiS alone, and half report that they teach the course with a colleague.

\section{School demographics}

Information on the technology background of the AiS schools and the demographic profiles of their teachers and student populations was collected from the principals of participating AiS schools. Further demographic data on eighteen schools was collected from Quality Education Data, a research firm that collects a range of data on schools and school districts. School demographic data helps us to understand the various contexts in which the AiS program is functioning.

Size and location of schools. The mean number of students enrolled in AiS schools is 940.2. This represents a range from a minimum of 66 students, to a maximum of 2,067 . A majority of AiS schools reported on in the administrator surveys are in rural settings: five are in rural non-farming communities; three are in farming communities; four are in small cities; and one is in a suburb.

Student demographics. These schools' student populations include an average of $40 \%$ minority students. An average of $20 \%$ of the student population in these schools is living below the poverty line - this number ranges from a low of $11 \%$ to a high of $39 \%$. The mean percentage of students from these schools who are college-bound is $60 \%$, ranging from a low of $30 \%$ to a high of $85 \%$.
Looking across these three statistics - minority population, percentage of students below the poverty line, and percentage of college-bound students - minority population in the AiS schools rises in direct relation to the percentage of students living below the poverty line, and in direct opposition to the number of students who are college bound. In other words, across the AiS sites, the larger the minority population in the school, the more students there are who are living below the poverty line, and the fewer of these students are college-bound.

Technology use in schools. The principals of AiS schools report an average of 8.1 years of educational technology use in their schools, ranging from a low of two years to a high of 11. They report $33.4 \%$ of their staff uses computers in their teaching; this proportion ranges from a low of $5 \%$ to a high of $95 \%$.

Student/teacher ratios. Student/teacher ratios for high school students in AiS schools range from $9 / 1$ to $28 / 1$, with an average of 19/1.

\section{STUDENT JOURNALS}

Because AiS students are spending an entire school year developing and revising complex research questions, an important component of the evaluation is understanding the development of their thinking over time. The journal data presented in this report focuses on the early stages of this process by analyzing students' motivations and incentives for involvement in the AiS program, as well as how and why they selected their project topics.

99\% of students reported having some kind of project topic. None of the students stated a complete and specific project hypothesis. While a considerable number of students (39.9\%) described specific questions their project would investigate, most stated general topics for their work $(59.3 \%)$. Their projects represent a range of topical interests, dominated by physics $(28.8 \%)$, which was followed in popularity by biomedical (12.3\%) and ecological or agricultural topics (12.3\%).

$60 \%$ of students report that they are working in project groups. Among these, consensus was most common mode of decision-making (39.7\% of students in groups), while some reported "lemming" behavior (7.6\%), voting (4.8\%), and unilateral decisions (3.4\%).

Three-quarters of these students report some kind of affective motivation for pursuing their project topic. The other $25 \%$ reported pragmatic motivations. Some students explained that this class was giving them an opportunity to investigate a subject that had been of great interest to them for years. For instance, one student explained that he had decided to investigate how far a baseball can travel under certain atmospheric conditions. He chose the topic "because baseball and science are two of my favorite things, so I tied them in together." 
Other students described a desire to do something that would contribute to a greater social good. One student wrote that she was going to study the genetics of sickle cell anemia because "two years ago in my biology class we discussed genetic diseases. Before that point I had always wanted to be a lawyer. The pictures that I saw made me feel so sorry for those children. That's when I made a decision to help them." Other students described a more serendipitous route to their topics: "my project is about how raindrops form after storms. I decided on the topic because it has been really rainy over the last couple of days. I was just curious about how the pretty rainbows form."

\section{DISCUSSION}

Through the analysis of demographic data on AiS students, teachers, and schools, we have gained some basic understanding of who is involved in the AiS program, and of the technological environments in which they are learning and working. Analysis of early journal entries has helped us begin to track the development of students' project work, their expectations of the course, and the kind of questions they intend to pursue during the rest of the year. Observations at school sites have given us clues to a range of issues that may prove to be important factors in students' experiences in the AiS program. Site visits have also helped us to gain a deeper understanding of the range of ways in which the AiS program is implemented in different school environments.

The dedication of the teachers involved in the AiS program has been overwhelmingly evident during school visits and on-line correspondence. Teachers in this program come from a broad range of types of schools, each with its own particular blend of strengths and limitations. AiS teachers have been willing to take on a program that requires them to engage with a type of interdisciplinary inquiry that is most likely new to them conceptually. Additionally, the program requires that they acquire a range of technical skills, and pass those skills on to their students. At times, the level of newly acquired knowledge teachers have demonstrated in their work with the AiS program has been truly amazing. Their ability to make the program work in schools that sometimes present a range of administrative obstacles is highly commendable as well.

\section{Making AiS inviting to a range of students}

A range of issues raised in the data suggests ways the program might be able to more actively invite women and minority students into taking an AiS course. In the September journals, the primary motivation for taking AiS was to "prepare for the future." The primary expectation students had of the course was that they would "learn about computers" and "learn to program them." This kind of language suggests that what students hear about the course may focus primarily on the attraction of simply being exposed to computers - to be physically close to them, to engage with them as exciting and novel objects of interest.
For many students, this is an attractive scenario worthy of great excitement. However, students who are not inclined to be compelled by the technological objects themselves, stressing the interdisciplinary and inquiry-oriented quality of the work that is facilitated by using the range of resources made available through AiS would offer a far different view of what supercomputing is about.

During site visits, questions to students about how they heard about the course offered support for this idea - some teachers attracted students by word of mouth, suggesting the course to students they thought would do well and asking them to tell their friends. In other schools, the course is taught under various headings - for instance, in one New Mexico school, AiS is taught under the aegis of "Advanced C programming" in the business department of the school. These two very different examples both probably lead to some degree of self-selection of certain students for the course, and miss opportunities to draw in students who might not find the course through the pathways illustrated here.

\section{Telecommunications in the classroom}

Barriers to complete integration of telecommunications into the AiS program include delays in establishing accounts, stringent restrictions on student access, and the inevitable learning curve as students and teachers become familiar with this resource. A balance needs to be struck between providing a responsible level of monitoring of student activity on the Internet, and allowing students the kind of flexible access to this resource that is necessary to support substantive independent work. Particularly in rural environments, students have spoken enthusiastically about the opportunity AiS provides them to explore distant and otherwise unavailable resources, and to correspond with adults and students from other schools and institutions. Finding systematic ways to help students become creative and responsible users of this resource will both alleviate frustrations for teachers and expand the pool of resources from which students can draw information, advice, and instruction.

\section{Mentors: Establishing and defining relationships}

Finding mentors for students and structuring mentoring relationships appropriately were prominent issues for many teachers during our site visits. Finding mentors was also a prominent topic for students. The issue is complicated in part because it both challenges teachers' practical capabilities - it is a time-consuming process, often requiring multiple phone calls and special trips - and because moving outside one's school environment and area of expertise is, for some teachers, a personally challenging task as well. This component is also relevant for students - some of whom relish the opportunity to meet and talk with new people, while others either find the process intimidating or don't see why such a person might be beneficial. Helping teachers to locate pre-existing mentoring networks, or 
helping them develop their own connections and resource lists, might alleviate some of these stresses.

Once mentors are found for students, it may also be important to develop materials to help them understand the role they can play in supporting students' work. At the fall workshop in one state a teacher passed out a sheet which she says she shares with her students' mentors, which specifies what she does and does not expect of them. Most mentors are university professors or scientific researchers who have no experience which would help them to be sensitive to the balance between guiding and directing a student through a project. One project team in Iowa, taking the class for a second year, explained that last year their mentor essentially solved their programming problem for them, which disappointed them because they were left without a challenge. This year they are resisting the idea of having a mentor at all.

Finally, the October journals demonstrated that students are beginning to pursue projects in a wide variety of content areas. While this speaks very well for the interdisciplinary nature of the work encouraged by the AiS program, it presents a challenge for teachers. In our site visits, the large majority of teacher contacts were in physical science and engineering fields. As demonstrated by the mentor in New Mexico who was able to distinguish his role in helping student groups with inquiry process behind their projects, regardless of their particular project content, mentors do not necessarily have to be content area experts to help students. Indeed, it would probably remain difficult even for the most well connected teacher to find exact matches between all student projects and mentors with expertise in the correct content area. However, students are likely to think of the content as the primary link to the mentor, as in the case of the students who wanted to investigate a genetics problem but could not find a geneticist to work with them. A balance needs to be struck between broadening the disciplinary areas from which mentors are drawn and helping teachers, students and mentors all to think creatively about what aspects of student projects mentors can best support.

\section{Integrating programming and project conceptualization}

Both site visits and student journals have shown us that most students involved in AiS have spent their fall semester learning or refining programming skills, selecting project topics, and beginning to carry out content research about their topic. Integrating these activities, however, is a challenge which many students do not fully accomplish in the Fall.

AiS teachers face a range of challenges associated with teaching programming. In many cases teachers have just learned, or are still learning, the programming language themselves and are not entirely secure with their material. In many classes teachers are working with students with a range of abilities as programmers - advanced students who know several languages may be working next to novice programmers who have never worked on a computer before. During many of our site visits we observed classes in which teachers responded to these difficulties by giving students uniform, isolated programming exercises which they were expected to work on independently, or by teaching students new programming skills in lockstep fashion. While students in these classes are likely to gain a degree of programming ability from carrying out these exercises, such exercises do not contribute to their understanding of the relationship between programming and the problems they are trying to solve in their projects. One teacher at the Tennessee fall workshop reported that he expects students to learn programming techniques as they need them - he expects students to identify needs which they then solve by learning to create programs that will help them solve the problem at hand. This approach suggests one way in which programming can be consistently tied to the kind of problem-solving AiS projects are expected to address.

Students may also benefit from a structured timeline, a set of project markers which enables them to chart and gauge their progress. Students in one New Mexico class, for instance, are given a project development schedule by their teacher. This document identifies specific project tasks (such as selecting a topic, locating a mentor, writing a project abstract, and writing project code) which build upon each other and are to be completed by certain points in the school year. By dividing the project into manageable tasks, the teacher is better able to monitor her students' successes and difficulties, and the students are more focused.

\section{REFERENCES}

Roschelle, J., \& Fredriksen, J. (1992). Technology choices, feasibility and use for video portfolio assessment. A report to the National Board of Professional Teaching Standards.

National Center for Education Statistics. (1993). Digest of Education Statistics, 1993. Washington, DC: U.S. Department of Education, Office of Educational Research and Improvement.

National Center for Education Statistics. (1992, July). Schools and staffing in the United States: A statistical profile, 1987-88. Washington, DC: U.S. Department of Education, Office of Educational Research and Improvement.

Sheingold, K, \& Hadley, M. (1990). Accomplished teachers: Integrating computers into classroom practice. New York: Bank Street College of Education, Center for Technology in Education. 


\title{
C. Edward Oliver
}

Dr. C. Edward Oliver received his Ph.D. in Mathematics in 1969 from the University of Alabama. He is the Associate Director of Oak Ridge National Laboratory for Computing, Networking, Informatics, and Education

\section{H. Richard Hicks}

Dr. H. Richard Hicks received his Ph.D. in Physics in 1971 from the University of Illinois. Hicks is in the Office of Laboratory Computing at Oak Ridge National Laboratory.

\section{Kimberly D. lles-Brechak}

Kimberly D. Iles-Brechak received a B.A. in 1990 from the University of Tennessee. She is a staff employee of Vanderbilt University.

\section{Margaret Honey}

Dr. Margaret Honey is the Associate Director of the Education Development Center's Center for Children and Technology. She holds a doctorate from Columbia University in Developmental Psychology.

\section{Katherine McMillan}

Katherine McMillan is a research associate at the Education Development Center's Center for Children and Technology. She is currently a doctoral candidate in Developmental Psychology at Columbia University.

\footnotetext{
* Managed by Martin Marietta Energy Systems, Inc., under contract DE-AC05-84OR21400 with the U.S. Department of Energy.
}

\section{DISCLAIMER}

\begin{abstract}
This report was prepared as an account of work sponsored by an agency of the United States Government. Neither the United States Government nor any agency thereof, nor any of their employees, makes any warranty, express or implied, or assumes any legal liability or responsibility for the accuracy, completeness, or usefulness of any information, apparatus, product, or process disclosed, or represents that its use would not infringe privately owned rights. Reference herein to any specific commercial product, process, or service by trade name, trademark, manufacturer, or otherwise does not necessarily constitute or imply its endorsement, recommendation, or favoring by the United States Government or any agency thereof. The views and opinions of authors expressed herein do not necessarily state or reflect those of the United States Government or any agency thereof.
\end{abstract}

